Cite this: J. Mater. Chem. A, 2014, 2, 5131

Received 21st November 2013 Accepted 21st January 2014

DOI: $10.1039 / \mathrm{c} 3 \operatorname{ta} 14815 \mathrm{~g}$

www.rsc.org/MaterialsA

\section{Kroll-carbons based on silica and alumina templates as high-rate electrode materials in electrochemical double-layer capacitors $\dagger$}

\author{
M. Oschatz, ${ }^{\text {a }}$ S. Boukhalfa, ${ }^{\text {b } W . ~ N i c k e l, ~}{ }^{\text {a }}$ J. T. Lee, ${ }^{\text {b }}$ S. Klosz, ${ }^{c}$ L. Borchardt, ${ }^{d}$ \\ A. Eychmüller, ${ }^{c}$ G. Yushin ${ }^{\star b}$ and S. Kaskel ${ }^{* a}$
}

Hierarchical Kroll-carbons (KCs) with combined micro- and mesopore systems are prepared from silica and alumina templates by a reductive carbochlorination reaction of fumed silica and alumina nanoparticles inside a dense carbon matrix. The resulting KCs offer specific surface areas close to $2000 \mathrm{~m}^{2} \mathrm{~g}^{-1}$ and total pore volumes exceeding $3 \mathrm{~cm}^{3} \mathrm{~g}^{-1}$, resulting from their hierarchical pore structure. High micropore volumes of $0.39 \mathrm{~cm}^{3} \mathrm{~g}^{-1}$ are achieved in alumina-based $\mathrm{KCs}$ due to the enhanced carbon etching reaction being mainly responsible for the evolution of porosity. Mesopore sizes are uniform and precisely controllable over a wide range by the template particle dimensions. The possibility of directly recycling the process exhaust gases for the template synthesis and the use of renewable carbohydrates as the carbon source lead to a scalable and efficient alternative to classical hard- and soft templating approaches for the production of mesoporous and hierarchical carbon materials. Silica- and aluminabased Kroll-carbons are versatile electrode materials in electrochemical double-layer capacitors (EDLCs). Specific capacitances of up to $135 \mathrm{~F} \mathrm{~g}^{-1}$ in an aqueous electrolyte ( $1 \mathrm{M}$ sulfuric acid) and $174 \mathrm{~F} \mathrm{~g}^{-1}$ in ionic liquid (1-ethyl-3-methylimidazolium tetrafluoroborate) are achieved when measured in a symmetric cell configuration up to voltages of 0.6 and $2.5 \mathrm{~V}$, respectively. $90 \%$ of the capacitance can be utilized at high current densities $\left(20 \mathrm{~A} \mathrm{~g}^{-1}\right.$ ) and room temperature rendering Kroll-carbons as attractive materials for EDLC electrodes resulting in high capacities and high rate performance due to the combined presence of micro- and mesopores.

\section{Introduction}

Porous carbon materials are of outstanding importance in various energy- and environmentally relevant fields such as gas adsorption, ${ }^{\mathbf{1 , 2}}$ catalysis, ${ }^{3-5}$ or water treatment ${ }^{6-8}$ because they combine large specific surface area with high chemical and thermal stability. Additionally, their high electrical conductivity makes them crucial components in various electrochemical energy storage devices. ${ }^{9-16}$ Among them, electrochemical double-layer capacitors (EDLCs) stand out due to their power densities, cycle life, and charge-discharge times which are unachievable by lithium-based batteries due to the absence of time consuming redox reactions. ${ }^{17}$ In EDLCs, the charge

${ }^{a}$ Inorganic Chemistry, TU Dresden, Bergstrasse 66, D-01062 Dresden, Germany. E-mail: stefan.kaskel@chemie.tu-dresden.de

${ }^{b}$ Department of Materials Science and Engineering, Georgia Institute of Technology, Atlanta, GA-30332, USA. E-mail: yushin@gatech.edu

'Physical Chemistry, TU Dresden, Bergstrasse 66b, D-01062 Dresden, Germany

${ }^{d}$ Institute for Chemical and Bioengineering, ETH Zürich, Wolfgang-Pauli-Strasse 10, CH-8093 Zurich, Switzerland

$\dagger$ Electronic supplementary information (ESI) available: KC synthesis, further material characterization and electrochemical data. See DOI: 10.1039/c3ta14815g accumulation is of purely physical nature based on the formation of an electrochemical Helmholtz double-layer on the surface of the usually carbonaceous electrode material. However, fast transport and rapid access of the electrolyte ions to the electrode surface area are required to achieve high power densities, especially when electrolyte systems with low ionic mobility (e.g. ionic liquids) are used. ${ }^{18}$ This can be ensured by lowering the carbon particle size down to the nanometer range ${ }^{19,20}$ or by the introduction of internal transport pores. ${ }^{18,21}$ While ion adsorption in narrow micropores results in high capacities, ${ }^{22-24}$ mesopore channels can serve as ion highways allowing for enhanced ion diffusion kinetics within the electrode..$^{25-29}$

In the current literature, many different routes for the synthesis of high-capacity microporous carbon materials are reported. Chemical or physical activation of carbonized natural or synthetic precursors produces carbon materials with moderate specific capacitances of usually $100-120 \mathrm{~F} \mathrm{~g}^{-1}$. The presence of bottle neck pores or torturous pores in the range of 0.3-4 $\mathrm{nm}^{30,31}$ may slow down the ion transport within large activated carbon (AC) particles and therefore limits their power characteristics. ${ }^{\mathbf{1 8 2 1 , 3 2}}$ However, advanced synthesis strategies for ACs with impressively high specific capacities have been 
reported $^{33-36}$ and they will remain one of the most promising electrode materials for EDLCs due to their well-known manufacturing techniques, comparably low cost, and easy production of large quantities. Zeolite-templated carbons (ZTCs) display another interesting class of materials because they consist of a very uniform micropore system and can be designed in a well-aligned structure. ${ }^{37-40}$ Alternatively, carbidederived carbons (CDCs) can be prepared by the selective etching of metal or semi-metal atoms from carbide precursors. ${ }^{41-43}$ With a few exceptions, ${ }^{44-46}$ the micropore size is narrow (usually $\leq 1 \mathrm{~nm}$ ) and precisely controllable by the carbon distribution within the carbide precursor and the synthesis temperature. ${ }^{\mathbf{4 1 , 4 2}}$ CDCs offer highly uniform pores with advanced accessibility due to the absence of bottle-necks. Microporous CDCs show specific capacitances up to $160 \mathrm{~F} \mathrm{~g}^{-1}$ but the ion transport is relatively slow in the narrow micropores and therefore they suffer from a moderate rate of charge-discharge. ${ }^{47}$

While microporous carbons can store large amounts of ions leading to high volumetric and gravimetric capacitances, purely mesoporous materials such as carbon onions ${ }^{28}$ or carbon nanotubes ${ }^{\mathbf{1 1}}$ are favorable for applications where ultrafast charge-discharge is required. But electrodes produced from such mesoporous carbon nanomaterials suffer from a comparably low specific surface area limiting the achievable energy density. Therefore, many mesoporous materials have been equipped with additional micropores to increase the ion storage capacity. In most cases, templated mesoporous carbons undergo a post-synthesis activation procedure ${ }^{48}$ or metal extraction for the insertion of micropores when the CDC process is applied to mesoporous carbide precursors. ${ }^{18,21,42,49}$ However, the mesopore generation in such hierarchically structured materials by very complex templating approaches often requires the use of extremely toxic hydrofluoric acid solution for efficient template removal or surfactant-assisted structure evolution making commercialization more difficult. In contrast to such complex templating approaches, physical and chemical activation do not allow precise control of mesopore sizes and therefore an ultimate process for the generation of carbon materials with welldefined mesopores is still not available.

Recently, we have reported the reductive carbochlorination (which is the key step of the Kroll-process for the production of elemental titanium) of $\mathrm{TiO}_{2}$ nanoparticle templates in a dense carbon matrix for the generation of highly mesoporous carbon materials (designated as Kroll-carbons, KCs). This new synthesis route allows precise control over the mesopore size and simultaneous formation of micropores in analogy to physical activation procedures leads to KCs with specific surface areas up to $2000 \mathrm{~m}^{2} \mathrm{~g}^{-1}$ coupled with total pore volumes as high as $3.1 \mathrm{~cm}^{3} \mathrm{~g}^{-1}$. The highly useful byproduct $\mathrm{TiCl}_{4}$ can be removed by distillation leading to a scalable production scheme for hierarchically structured carbons with high performance in lithium-sulfur battery cathodes. ${ }^{50}$ Because this method is highly versatile for producing porous carbon materials with different structures, it is of interest to extend it to a large number of different oxidic templates.

We present in the following that carbochlorination using commercially available fumed silica and alumina templates is a versatile alternative for the production of porous carbons at lowcost. Infiltration with sucrose followed by carbonization and subsequent high-temperature chlorination leads to the formation of KCs with specific surface areas close to $2000 \mathrm{~m}^{2} \mathrm{~g}^{-1}$ and total pore volumes as high as $3.2 \mathrm{~cm}^{3} \mathrm{~g}^{-1}$ with contributions from both the micropore- and mesopore regions. Due to the formation of additional micropores during template removal by reductive carbochlorination, the specific surface areas of the carbons significantly exceed the values achievable by classical hard-templating approaches using hydrofluoric acid for the removal of template particles of comparable dimensions. ${ }^{51}$ Despite the fact that chlorination at high temperatures is a dangerous and toxic process, the reductive carbochlorination is highly efficient because the corresponding metal chlorides can be obtained as very useful byproducts. $\mathrm{SiCl}_{4}$ could be directly reused for the $\mathrm{SiO}_{2}$ template synthesis by flame spray pyrolysis. Mesopore sizes are precisely controllable by the template particle dimensions while the applied synthesis temperature only has minor influence on the properties of the resulting materials. KCs are tested as electrode materials in EDLCs based on aqueous and ionic liquid (IL) electrolytes. Due to the presence of the hierarchical pore structure, they combine high capacities with outstanding rate capability rendering them as advanced materials for EDLCs. Especially in the IL electrolyte, KCs show high stability and a wide operating window leading to advanced energy density, rendering reductive carbochlorination as a promising route for large-scale production of hierarchically structured carbon for use in high-power EDLCs.

\section{Experimental}

\section{Kroll-carbon synthesis}

For the synthesis of Kroll-carbons based on $\mathrm{Al}_{2} \mathrm{O}_{3}$ templates, $2.54 \mathrm{~g}$ of commercially available alumina nanoparticles (Aeroxide Alu 130; Degussa-Evonik, Germany; specific surface area of $130 \pm 20 \mathrm{~m}^{2} \mathrm{~g}^{-1}$ ) were dispersed in a solution of $5.0 \mathrm{~g}$ sucrose in $80 \mathrm{ml}$ deionized water followed by the addition of 8 droplets ( $\sim 160 \mathrm{mg}$ ) of concentrated sulfuric acid. For KCs based on $\mathrm{SiO}_{2}$ templates, $2.0 \mathrm{~g}$ of commercially available silica nanoparticles (Aerosil 380 or Aerosil 90; Degussa-Evonik, Germany; specific surface areas of $380 \pm 30 \mathrm{~m}^{2} \mathrm{~g}^{-1}$ for Aerosil 380 and $90 \pm 15 \mathrm{~m}^{2} \mathrm{~g}^{-1}$ for Aerosil 90) were dispersed in a solution of $4.75 \mathrm{~g}$ sucrose in $10 \mathrm{ml}$ deionized water followed by the addition of 2 droplets $(\sim 40 \mathrm{mg})$ of concentrated sulfuric acid. The mixture was transferred to a Petri dish and treated for $3 \mathrm{~h}$ at $100{ }^{\circ} \mathrm{C}$ and for another $3 \mathrm{~h}$ at $160{ }^{\circ} \mathrm{C}$ in air atmosphere. The resulting black composite was then carbonized under an argon flow of $150 \mathrm{ml} \mathrm{min}{ }^{-1}$ at 900 or $1000^{\circ} \mathrm{C}$ for $1 \mathrm{~h}$ (heating rate $300 \mathrm{~K} \mathrm{~h}^{-1}$ ). Subsequently, the gas flow was changed to a mixture of $80 \mathrm{ml} \mathrm{min}^{-1}$ chlorine and $70 \mathrm{ml} \mathrm{min} \mathrm{m}^{-1}$ argon while the temperature was maintained for another $2 \mathrm{~h}$. The resulting Kroll-carbon was cooled down to $600{ }^{\circ} \mathrm{C}$ under $150 \mathrm{ml} \mathrm{min}{ }^{-1}$ of flowing argon and maintained at that temperature for $1 \mathrm{~h}$ followed by changing the gas flow to $80 \mathrm{ml}$ $\min ^{-1}$ hydrogen for another $1 \mathrm{~h}$. Samples were then cooled down to room temperature under flowing argon. 


\section{Material characterization}

Nitrogen physisorption experiments were carried out at $-196{ }^{\circ} \mathrm{C}$ on an Autosorb 1C instrument (Quantachrome Instruments). Specific surface areas $\left(\mathrm{SSA}_{\mathrm{BET}}\right)$ were calculated using the multipoint BET equation $\left(p / p_{0}=0.05-0.2\right)$. Total pore volumes $\left(\mathrm{PV}_{\text {Total }}\right)$ were determined at $p / p_{0}=0.99$. Pore size distributions (PSDs) were calculated using the quenched-solid density functional theory (QSDFT) method (adsorption branch kernel) for nitrogen adsorbed on carbon with a slit/cylindrical/spherical pore shape at $-196^{\circ} \mathrm{C}$. Specific surface area values $\left(\mathrm{SSA}_{\mathrm{DFT}}\right)$ and total pore volumes $\left(\mathrm{PV}_{\mathrm{DFT}}\right)$ were also obtained from this kernel. Micropore volumes $\left(\mathrm{PV}_{\mathrm{Micro}}\right)$ correspond to the cumulative pore volumes at a diameter of $2 \mathrm{~nm}$. Furthermore, the $t$-plot method $\left(p / p_{0}=0.3-0.4\right)$ was used for the calculation of the micropore volume $\left(\mathrm{PV}_{t \text {-plot }}\right)$.

Transmission electron microscopy (TEM) investigations were carried out using a Tecnai $G^{2}$ F30 (FEI, Netherlands) operating at an accelerating voltage of $300 \mathrm{kV}$. Scanning electron microscopy (SEM) measurements of gold sputtered samples were performed using a DSM982 (Zeiss). The same instrument was used for energy-dispersive X-ray spectroscopy (EDS) analyses. Elemental analyses are an average value of 3-5 measurements at a magnification of 5000. Raman spectra were obtained on a Renishaw RM-2000 Raman microscope using a $532 \mathrm{~nm}$ laser (Gem532, Laser Quantum) as the excitation source. Thermal analyses were performed using a STA 409 PC LUXX (Netzsch) with a heating rate of $5 \mathrm{~K} \mathrm{~min}^{-1}$ under oxidizing conditions (synthetic air).

\section{Electrode preparation and EDLC device assembly}

The KCs were ground to fine powders in a mortar and $~ 100 \mathrm{mg}$ were suspended in ethanol under mild ultra-sonication. A suspension of a polytetrafluoroethylene binder (PTFE, 60 wt $\%$ in water, Sigma Aldrich) was added and the resulting slurry of 5 wt\% PTFE and $95 \mathrm{wt} \%$ of carbon was concentrated by slow evaporation of ethanol at $80{ }^{\circ} \mathrm{C}$ under constant stirring. The highly viscous mixture was then dried on a glass plate and mixed with a spatula or razor blades. When the mass became dry with a rubberlike (clay) consistency, it was rolled to a thickness of $\sim 150 \mu \mathrm{m}$ between aluminium foil sheets using a commercial roll mill. The resulting composites were dried overnight at $80{ }^{\circ} \mathrm{C}$ under vacuum.

For the measurements in the aqueous electrolyte $\left(1 \mathrm{M} \mathrm{H}_{2} \mathrm{SO}_{4}\right.$ solution), electrodes of $\sim 1 \mathrm{~cm}^{2}$ (2-3 $\mathrm{mg}$ active material) were cut out and the device assembly took place under air atmosphere. A high-purity gold foil (Sigma Aldrich, USA) was used as the current collector and a commercially available Dreamweaver Silver separator (Dreamweaver International, Inc., USA) was placed between the electrodes. The sandwich was assembled in a beaker-type cell configuration and held together using Teflon slabs and screws. Sufficient wetting of the porous carbon electrodes with sulfuric acid was ensured by adding an excess of electrolyte solution to the beaker followed by a treatment under vacuum at RT for $1 \mathrm{~h}$.

For the measurements in 1-ethyl-3-methylimidazolium tetrafluoroborate $\left(\mathrm{EMIBF}_{4},>98 \%\right.$, IoLiTec Ionic Liquids
Technologies GmbH, Germany) ionic liquid electrolytes the devices were assembled in a stainless steel coin cell configuration in an argon filled glovebox. Carbon coated aluminium foil was used as the current collector and the above mentioned Dreamweaver product as the separator. 4-5 droplets of the electrolyte were used for the wetting of the electrodes and the separator and the excess amount was removed during compression of the coin cell. For electrochemical measurements, aluminium contacts were fixed to the coin cells with plastic clamps.

\section{EDLC measurements}

Electrochemical characterization of the KC-based EDLC devices was carried out using cyclic voltammetry (CV), galvanostatic charge-discharge (C-D), and electrochemical impedance spectroscopy (EIS) experiments. CV measurements were performed on a Solartron 1480A (AMETEK Advanced Measurement Technology) in a potential range from $-0.6 \mathrm{~V}$ to $+0.6 \mathrm{~V}$ (aqueous electrolyte) or $-2.0 \mathrm{~V}$ to $2.0 \mathrm{~V}$ (ionic liquid electrolyte) at scan rates of 1-1000 $\mathrm{mV} \mathrm{s}^{-1}$. The gravimetric capacitance of each electrode at different scan rates was calculated from the CV data according to:

$$
\begin{aligned}
C_{\text {electrode }}=2 C_{\text {cell }}= & \left(\frac{2}{(\mathrm{~d} U / \mathrm{d} t) m}\right) \\
& \times\left\{\int_{-0.6 \mathrm{~V}}^{0.6 \mathrm{~V}} I(U) \mathrm{d} U-\int_{-0.6 \mathrm{~V}}^{0.6 \mathrm{~V}} I(U) \mathrm{d} U\right\} \frac{1}{2} \frac{1}{1.2 \mathrm{~V}}
\end{aligned}
$$

where $\mathrm{d} U / \mathrm{d} t$ is the scan rate, $m$ is the mass of the active material in a single electrode, and $I(U)$ is the total current. C-D experiments from $-0.6 \mathrm{~V}$ to $+0.6 \mathrm{~V}$ at charge/discharge current densities from $0.1-20 \mathrm{~A} \mathrm{~g}^{-1}$ (based on the mass of a single electrode) were carried out with an Arbin SCTS supercapacitor testing system (Arbin Instruments). The specific capacitance was calculated according to:

$$
C_{\text {electrode }}=2 C_{\text {cell }}=\left(\frac{2 I}{(\mathrm{~d} U / \mathrm{d} t) m}\right)
$$

where $I$ is the total current, $\mathrm{d} U / \mathrm{d} t$ is the slope of the discharge curve, and $m$ is the mass of active material in a single electrode. EIS measurements were performed on a Gamry Potentiostat from $100 \mathrm{kHz}-1 \mathrm{mHz}$ with a $10 \mathrm{mV}$ alternating current (AC) amplitude.

\section{Results and discussion}

\section{Structure and porosity}

KCs were obtained by infiltration of commercially available pyrogenic alumina or silica template particles with an aqueous solution of sucrose as the carbon precursor followed by carbonization under an inert atmosphere (ESI, Fig. S1 $\dagger$ ). Subsequent template removal was performed by a reductive carbochlorination reaction under a hot chlorine atmosphere leading to the formation of volatile metal chloride species and carbon monoxide according to: 


$$
\begin{gathered}
\mathrm{Al}_{2} \mathrm{O}_{3}+(3+x) \mathrm{C}+3 \mathrm{Cl}_{2} \rightarrow 2 \mathrm{AlCl}_{3(\mathrm{~g})}+3 \mathrm{CO}_{(\mathrm{g})}+x \mathrm{C} \\
\mathrm{SiO}_{2}+(2+x) \mathrm{C}+2 \mathrm{Cl}_{2} \rightarrow \mathrm{SiCl}_{4(\mathrm{~g})}+2 \mathrm{CO}_{(\mathrm{g})}+x \mathrm{C}
\end{gathered}
$$

At a chlorination temperature of $900{ }^{\circ} \mathrm{C}$, Aerosil Alu 130 as well as Aerosil 380 and 90 template particles are quantitatively removed from the oxide/carbon composites leading to the formation of highly pure Kroll-carbons. The carbon content of the samples measured with EDS is about 99 atom\% (Table 1). Potential impurities of $\mathrm{Si}, \mathrm{Al}, \mathrm{O}$ and $\mathrm{Cl}$ are below the detection limit. Accordingly, thermal analyses of the KCs under oxidative conditions (air atmosphere) up to $1000{ }^{\circ} \mathrm{C}$ show complete combustion of the carbon materials (ESI, Fig. S2 $\dagger$ ). Due to the complete template removal, KCs offer a highly open and accessible mesopore structure as shown by TEM investigations (Fig. 1). The mesopore sizes increase from values significantly below $30 \mathrm{~nm}$ in the KCs derived from Alu 130 and Aerosil 380 to diameters above $40 \mathrm{~nm}$ for the Aerosil 90 particles rendering the template removal by the reductive carbochlorination reaction as being highly conformal allowing precise control over the pore sizes of the resulting KCs.

One of the most important properties of porous carbon materials for use in EDLCs is the carbon microstructure because it strongly influences the electrical conductivity, interactions with the electrolyte ${ }^{27,52}$ and double-layer formation. ${ }^{53}$ TEM images at higher magnifications show the carbon microstructure as an arrangement of mostly disordered $\mathrm{sp}^{2}$ carbon fringes with a low degree of graphitization as it is typical for carbon materials prepared at comparable temperatures (Fig. 1B). Raman spectroscopy (Fig. 2) is another useful tool for the investigation of the carbon microstructure at a larger scale..$^{54}$ In accordance with the TEM investigations, the spectra indicate a highly disordered carbon structure due to the presence of the characteristic D band at $\sim 1350 \mathrm{~cm}^{-1}$. The shoulder D2 band present in all samples and the absence of sharp peaks in the range from $2400 \mathrm{~cm}^{-1}-3000 \mathrm{~cm}^{-1}$ also indicate a low graphitization in the KCs at the elevated synthesis temperature. However, the higher $I_{\mathrm{D}} / I_{\mathrm{G}}$ ratio (Table 1) of the Alu 130-derived Kroll-carbon as well as the lower full width at half maximum (FWHM) of its D band $\left(135 \mathrm{~cm}^{-1}\right)$ compared to the KCs obtained from Aerosil $380\left(136 \mathrm{~cm}^{-1}\right)$ and Aerosil $90\left(141 \mathrm{~cm}^{-1}\right)$ templates indicates a slightly higher amount of graphitic ribbon structures in this sample.

The pore structure of the hierarchically structured KCs was investigated with nitrogen physisorption experiments at $-196{ }^{\circ} \mathrm{C}$ (Fig. 3 and Table 1). High specific surface areas of $1867 \mathrm{~m}^{2} \mathrm{~g}^{-1}$ and total pore volumes of more than $3 \mathrm{~cm}^{3} \mathrm{~g}^{-1}$ are obtained by using alumina and silica templates, respectively. Because the adsorption isotherms in the case of the KCs derived

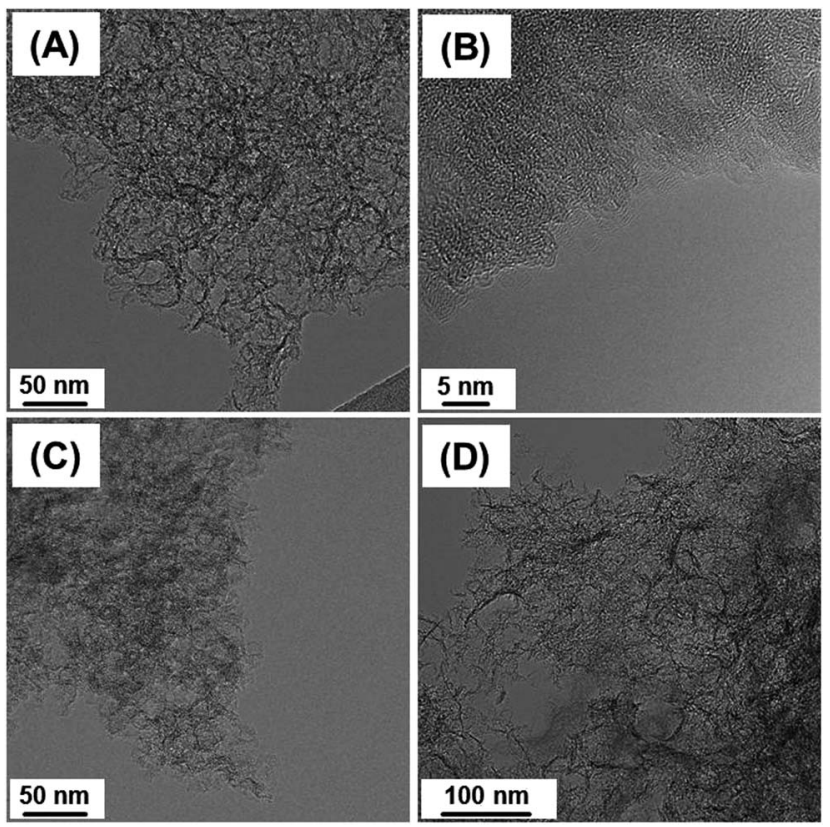

Fig. 1 TEM images of KCs from Alu 130 (A and B), Aerosil 380 (C), and Aerosil 90 (D)

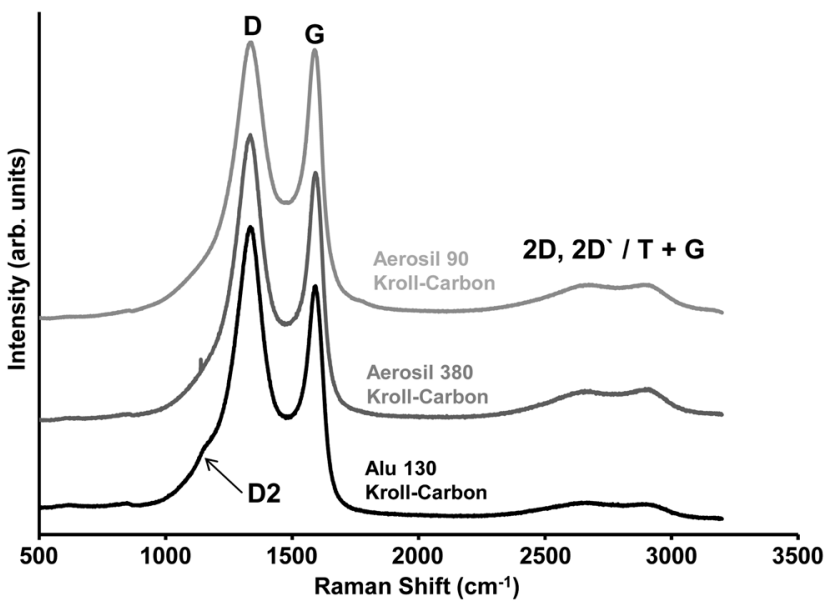

Fig. 2 Raman spectra of KCs from Alu 130, Aerosil 380, and Aerosil 90.

from silica templates do not reach saturation at $p / p_{0}=0.99$ these values must be regarded as minimum total pore volumes and the actual values might be even higher. The distinct uptake of nitrogen at low relative pressures $\left(p / p_{0}<0.1\right)$ is associated with the filling of narrow micropores which are generated by the CO evolution during carbochlorination in analogy to physical

\begin{tabular}{|c|c|c|c|c|c|}
\hline Template & $I_{\mathrm{D}} / I_{\mathrm{G}}$ & Carbon [atom\%] & $\operatorname{SSA}_{\mathrm{BET}}\left(\mathrm{SSA}_{\mathrm{DFT}}\right)\left[\mathrm{m}^{2} \mathrm{~g}^{-1}\right]$ & $\mathrm{PV}_{\text {Total }}\left(\mathrm{PV}_{\text {DFT }}\right)\left[\mathrm{cm}^{3} \mathrm{~g}^{-1}\right]$ & $\mathrm{PV}_{\text {Micro }}\left(\mathrm{PV}_{t \text {-plot }}\right)\left[\mathrm{cm}^{3} \mathrm{~g}^{-1}\right]$ \\
\hline Alu 130 & 1.54 & 99.1 & $1867(1635)$ & $1.92(1.80)$ & $0.39(0.31)$ \\
\hline Aerosil 380 & 1.40 & 98.9 & $1710(1559)$ & $3.24(2.57)$ & $0.32(0.25)$ \\
\hline
\end{tabular}

Table 1 Raman and EDS spectroscopy analyses as well as porosity data summary of the KCs 


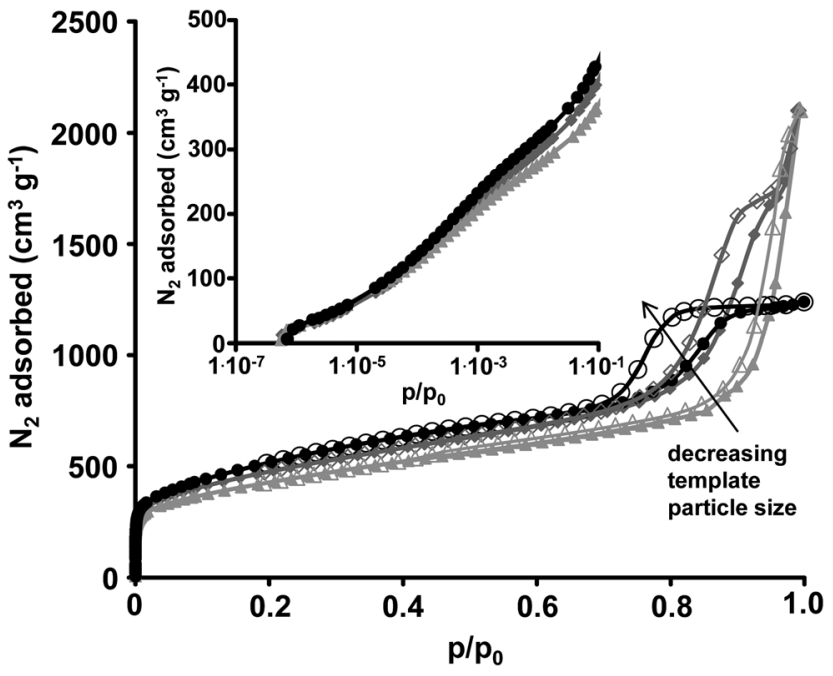

Fig. 3 Nitrogen adsorption/desorption (filled symbols/empty symbols) isotherms $\left(-196{ }^{\circ} \mathrm{C}\right)$ of the KCs prepared from Aerosil 90 (light grey triangles), Aerosil 380 (dark grey diamonds), and Alu 130 (black circles) templates. The semi-logarithmic plot in the inset shows the adsorption in the low pressure region.

activation procedures and previously reported Kroll-carbons based on $\mathrm{TiO}_{2}$ templates. QSDFT-PSDs (Fig. 4) show the presence of $1 \mathrm{~nm}$ sized micropores and small volumes of narrow mesopores of 2-6 $\mathrm{nm}$ in size depending on the template. The latter are a result of the presence of empty spaces between the template nanoparticles due to incomplete filling of their voids with precursor molecules during infiltration as already reported for $\mathrm{TiO}_{2}$-derived KCs. ${ }^{50}$ Due to the higher molar ratio of carbon etching and therefore the preferred introduction of micropores, the highest specific surface areas and micropore volumes are obtained for KCs from the alumina template (Table 1) being responsible for the higher amount of adsorbed gas in the low pressure region. The $1 \mathrm{~nm}$ sized micropores are large enough for relatively fast and effective electrosorption of ions and small enough to serve for high specific and volumetric surface area available for double layer formation. According to prior reports, ion solvation shells become distorted in such small pores and can even be partially removed, thus increasing the capacitance due to smaller charge separation distance between the ion centres and the pore walls. ${ }^{22}$

All materials show a very distinct and narrow hysteresis loop at high relative pressures $\left(p / p_{0}>0.7\right)$ indicating the presence of
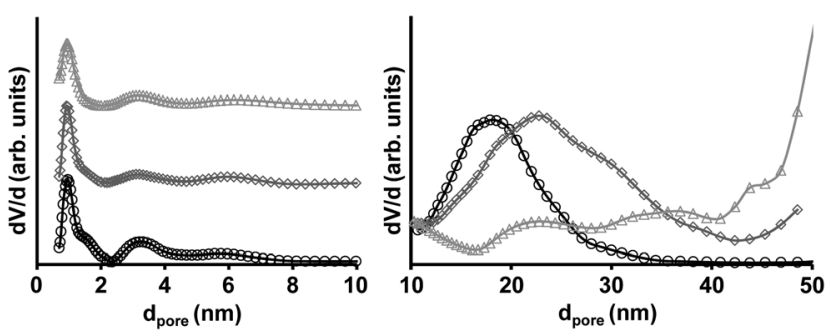

Fig.4 QSDFT pore size distributions of the KCs prepared from Aerosil 90 (light grey triangles), Aerosil 380 (dark grey diamonds), and Alu 130 (black circles) templates. high volumes of uniformly sized mesopores. According to the template particle sizes, the largest mesopores are obtained from the Aerosil 90 templates indicated by the pore filling at the highest relative pressures while Aerosil 380 and Alu 130 particles result in smaller pore diameters. No blocking or cavitation effects are observed due to the highly accessible mesopore systems present in the KCs. QSDFT-PSDs in the large mesopore region show template-induced mesopores centered at $18 \mathrm{~nm}$ and $23 \mathrm{~nm}$ for the Alu 130 and Aerosil 380 templates, respectively. The majority of mesopores present in KCs derived from Aerosil 90 are too large to be analysed by the QSDFT model. The distinct mesopore systems of the KCs ensure a high accessibility of the surface area throughout the entire particle. The additional microporosity is mainly responsible for the high specific surface area, which is not achievable by classical hardtemplating approaches of oxidic template particles of comparable size. ${ }^{51}$

SEM micrographs of the silica-based KCs (Fig. 5) show the additional presence of macropores already present in the templates and which are not infiltrated with the precursor. They are responsible for the additional gas uptake in the nitrogen physisorption at high relative pressures and can serve as additional ion transport pathways and allow rapid access of the entire particle. As already indicated by the saturation of the nitrogen physisorption isotherm, such pores are not present in the alumina-based KC due to a rather dense particle structure and the absence of large meso- or macropores (Fig. S3 $†$ ). In the KCs derived from Aerosil 90 particles, the large mesopores are clearly observed and their size of $40-70 \mathrm{~nm}$ is significantly higher as for the Aerosil 380-based sample in accordance with the nitrogen physisorption experiments again proving the precise control over the pore sizes provided by the reductive carbochlorination reaction.

We have also investigated the influence of the synthesis temperature on the properties of the resulting KCs. An increase of the pyrolysis/chlorination temperature to $1000{ }^{\circ} \mathrm{C}$ only slightly affects the properties independent of the used template particles (ESI, Fig. S4, S5 and Table S1 $\dagger$ ). The $I_{\mathrm{D}} / I_{\mathrm{G}}$ ratios are in

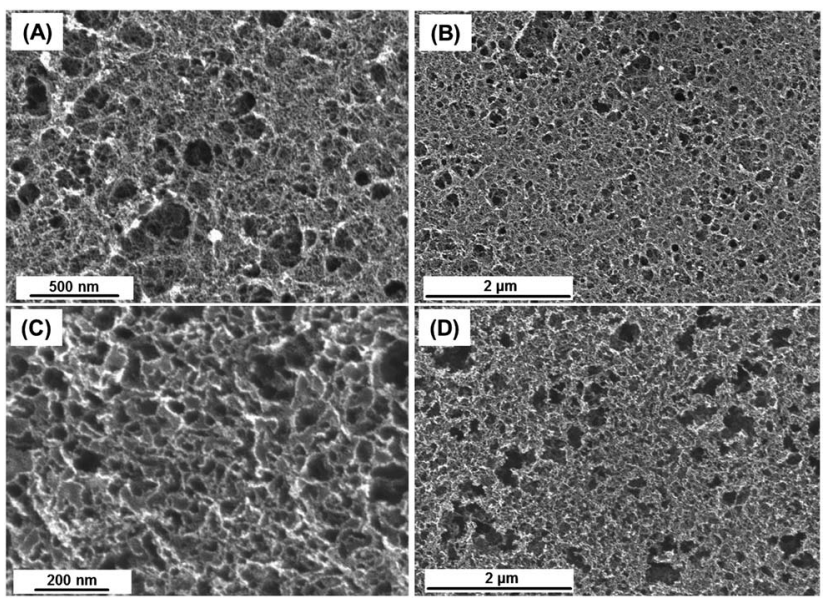

Fig. 5 SEM images of KCs from Aerosil 380 (A and B) and Aerosil 90 (C and D). 
the same range as for the materials prepared at $900{ }^{\circ} \mathrm{C}$ indicating a comparable degree of graphitization. The hightemperature samples exhibit a similar pore structure as shown by the nitrogen physisorption measurements and SEM images. EDS measurements reveal complete template removal at $1000{ }^{\circ} \mathrm{C}$ as well. From an ecological and economical viewpoint, the synthesis at $900{ }^{\circ} \mathrm{C}$ is beneficial because the advantages of the reductive carbochlorination route for the production of welldefined mesoporous carbon materials are fully achievable even at the lower temperature.

\section{EDLC performance}

The KCs derived from Alu 130 and Aerosil 90 templates (corresponding to the smallest and largest mesopores) were characterized as electrode materials in EDLCs (Fig. S6 $\dagger$ ) based on aqueous $\left(1 \mathrm{M} \mathrm{H}_{2} \mathrm{SO}_{4}\right)$ and ionic liquid $\left(\mathrm{EMIBF}_{4}\right)$ electrolytes (Table S2 $\dagger$ ). While aqueous electrolytes offer the advantages of high ionic conductivity and low cost, they suffer from narrow stability (usually they operate below $1 \mathrm{~V}$ due to the decomposition of water) limiting the achievable energy density. ${ }^{12}$ Ionic liquids exhibit large thermal- and higher voltage stability and therefore higher energy density but the mobility of ions within this electrolyte system is significantly lower leading to slow charge/discharge limiting the achievable power density within this electrolyte system especially in the absence of transport pores. The ionic liquid used in this study, $\mathrm{EMIBF}_{4}$, has recently shown to be a promising ionic liquid electrolyte with a relatively high ionic conductivity $\left(15.7 \mathrm{mS} \mathrm{cm} \mathrm{cm}^{-1}\right)$ and low viscosity $(36.2 \mathrm{cP})$ at room temperature. ${ }^{18,35}$

\section{Aqueous electrolyte}

The CV curves of the KCs in a $1 \mathrm{M}$ aqueous $\mathrm{H}_{2} \mathrm{SO}_{4}$ electrolyte are of rectangular shape within the applied potential range, indicating the absence of a large number of surface functional groups and the high purity of the materials (Fig. 6 and S7 $\dagger$ ). Capacitances as high as $135 \mathrm{~F} \mathrm{~g}^{-1}$ are obtained at $1 \mathrm{mV} \mathrm{s}^{-1}$ for the alumina-derived KCs due to their higher specific surface areas and micropore volumes compared to the silica-derived analogues showing a $26 \%$ lower value. While these are high values, our initial expectations based on the well-developed porosity (Fig. 3 and 4) were slightly higher. We hypothesize that the hydrophobic nature of the carbon surface may have prevented access of aqueous electrolytes to some of the smallest pores, an argument which in microporous carbons has been recently supported by small angle neutron scattering (SANS) analysis.$^{55}$ Moreover, the adsorption potential of ions within the large volumes of mesopores is lower compared to strictly microporous materials. ${ }^{22}$ This also explains the moderate capacitance per surface area of the KCs in this electrolyte system $\left(7.2 \mu \mathrm{F} \mathrm{cm}{ }^{-2}\right.$ for KCs prepared from Alu 130 templates and 6.6 $\mu \mathrm{F} \mathrm{cm}^{-2}$ for KCs prepared from Aerosil 90 templates).

The nearly rectangular shape of the CV curves at high sweep rates indicates very rapid ion diffusion in the materials due to their distinctive mesopore system. Specific capacitances up to $90 \mathrm{~F} \mathrm{~g}^{-1}$ can be utilized at a scan rate as high as $500 \mathrm{mV} \mathrm{s}^{-1}$, significantly exceeding the values of purely microporous carbon

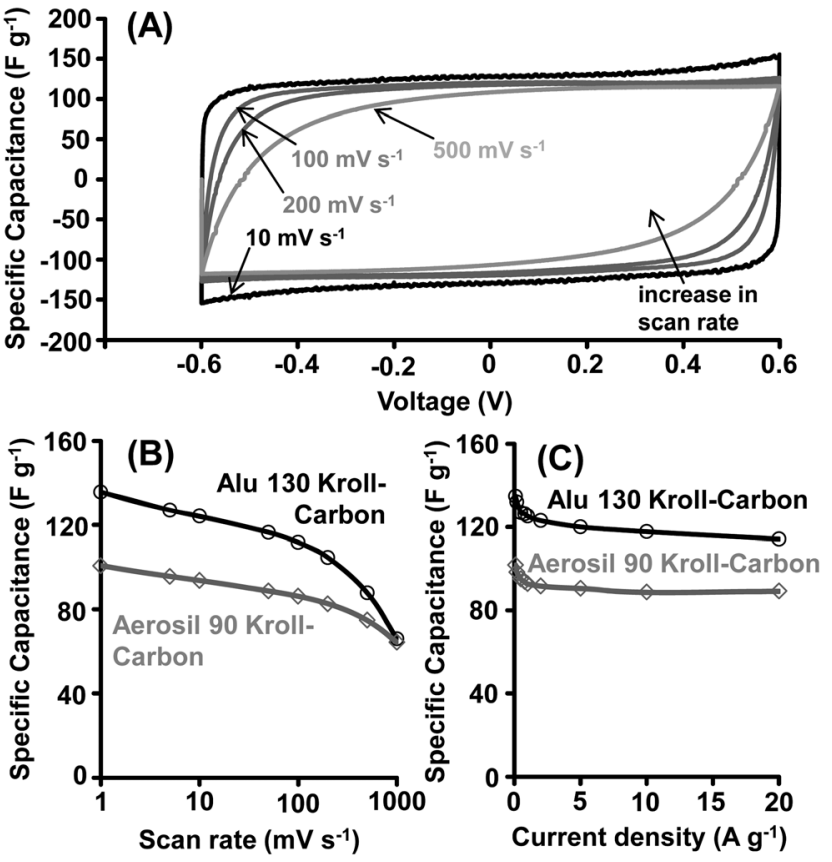

Fig. 6 Cyclic voltammograms of the KC obtained from Alu 130 template particles (A), specific capacitances of the KCs from Alu 130 (black circles) and Aerosil 90 (grey diamonds) at different $\mathrm{CV}$ scan rates (B), and galvanostatic $\mathrm{C}-\mathrm{D}$ measurements (C) in a $1 \mathrm{M} \mathrm{H}_{2} \mathrm{SO}_{4}$ electrolyte.

materials with curved pores that usually exhibit significant capacitance fading at higher scan rates. ${ }^{18}$ Only zeolite-templated strictly microporous carbons with straight pores offer comparable capacitance retention. ${ }^{39}$

The values determined by CV measurements are in good agreement with galvanostatic charge-discharge experiments (Fig. 6C and S8 ${ }^{\text {) }}$ ) showing specific capacitances up to $134 \mathrm{~F} \mathrm{~g}^{-1}$ and $101 \mathrm{~F} \mathrm{~g}^{-1}$ for the KCs derived from Alu 130 and Aerosil 90 templates, respectively (at $0.1 \mathrm{~A} \mathrm{~g}^{-1}$ ). C-D measurements are most accurate to determine the performance of EDLCs in real applications. In principle, an (ideal) EDLC must deliver the same amount of energy independent of the current density. However, in practical experiments a more or less distinct decrease of the available capacitance is observed due to the resistance of ions during transportation through the pore channels and their interaction with carbon functional groups and defects. C-D investigations independently prove the outstanding electron transport properties and therefore impressive high-power characteristics of KCs. $88 \%$ and $85 \%$ of the initial capacitance (at $0.1 \mathrm{~A} \mathrm{~g}^{-1}$ ) can be retained at high current densities of $20 \mathrm{~A} \mathrm{~g}^{-1}$. Such high capacitance retentions are not achievable with most commercial activated carbons optimized for EDLC devices. The commercial activated carbons, while showing comparable specific surface area usually retain only $50 \%$ of their initial capacitance at high current densities in the same electrolyte system. ${ }^{18}$

Nyquist plots of the KCs show a nearly vertical line at low frequencies, where the contribution becomes almost exclusively capacitive (Fig. 7, inset). The EIS measurements allow for 
estimation of the capacitance changes with the operating frequency (Fig. 7). At low frequencies, the capacitance shows saturation in both materials indicating that they reach the equilibrium in ion adsorption. The maximum operating frequency $\left(f_{\max }\right)$ is approximately the frequency at which the capacitance decreases by not more than 50\%. The Aerosil 90derived KCs can operate at higher frequency $(>1 \mathrm{~Hz})$ compared to the Alu 130-based sample $(>0.2 \mathrm{~Hz})$ due to its larger mesopores leading to enhanced ion diffusion. The equivalent series resistance (ESR) is a very important characteristic of an EDLC device including the electrical resistance of the electrodes and the current collector interfaces as well as the portion of the ionic resistance related to the ion transport outside of the carbon pore channels. It can be determined at very high frequencies when the imaginary component of the complex impedance becomes zero (intersection of the Nyquist plot with the $x$-axis). We see that the microstructure of Aerosil 90-derived KC architecture allows smaller equivalent series resistance to be attained, likely originating from the smaller current collector/ electrode contact resistance. The $f_{\max }$ of the silica-based sample is comparable to previously reported hierarchical materials and significantly surpassing the performance of activated carbons in the same electrolyte system. ${ }^{18}$

\section{Ionic liquid electrolyte}

The CV curves of the KC-based electrodes in the IL electrolyte show the presence of pseudocapacitance contributions at $\sim 1.7 \mathrm{~V}$ in the symmetrical EDLC (Fig. 8 and Fig. S9†). In accordance with prior work, these peaks may either result from impurities present in the $\mathrm{EMIBF}_{4}$ or from reactions of the IL with functional groups on the carbon surface. ${ }^{18,35}$ However, those Faradaic processes do not negatively affect the cycle stability of the EDLC showing complete retention of the initial capacitance after 10000 galvanostatic charge/discharge cycles $(-2.0 \mathrm{~V}$ to $+2.0 \mathrm{~V}$, ESI, Fig. S10 $\dagger)$. High specific capacitance values of $141 \mathrm{~F} \mathrm{~g}^{-1}\left(7.6 \mu \mathrm{F} \mathrm{cm}{ }^{-2}\right.$ related to KC surface area) for KCs prepared from Alu 130 templates and $124 \mathrm{~F} \mathrm{~g}^{-1}(8.1 \mu \mathrm{F}$ $\mathrm{cm}^{-2}$ ) for KCs prepared from Aerosil 90 templates are determined from the CV measurements at low scan rates. When the rate increases up to 100 or even $500 \mathrm{mV} \mathrm{s}^{-1}$, high specific

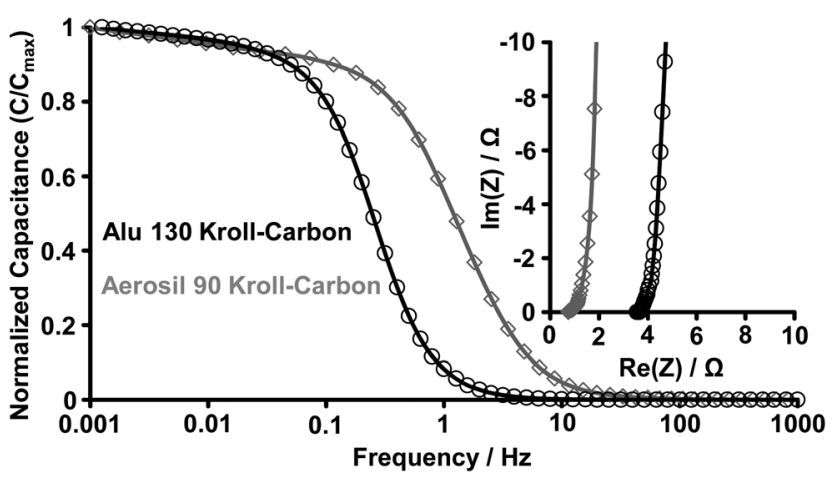

Fig. 7 Frequency response and Nyquist plots (inset) of the KCs from Alu 130 (black circles) and Aerosil 90 (grey diamonds) templates in the $1 \mathrm{M} \mathrm{H}_{2} \mathrm{SO}_{4}$ electrolyte.
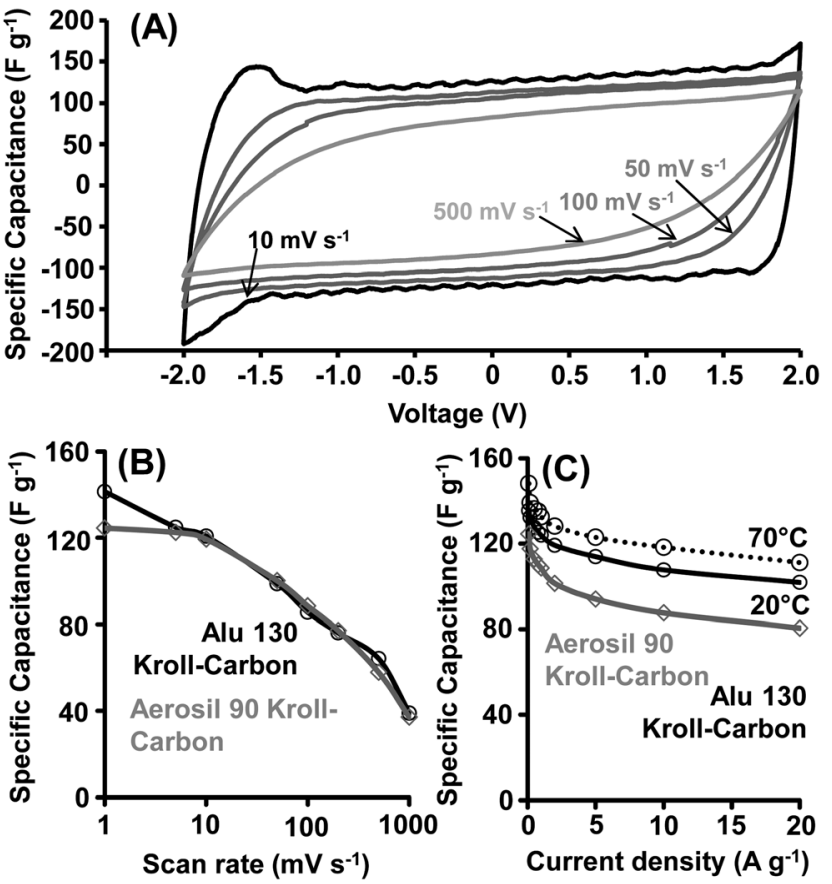

Fig. 8 Cyclic voltammograms of the KC obtained from Alu 130 template particles (A), specific capacitances of the KCs from Alu 130 (black circles) and Aerosil 90 (grey diamonds) at different CV scan rates (B), and galvanostatic C-D measurements (C) at $20^{\circ} \mathrm{C}$ (straight lines) and $70{ }^{\circ} \mathrm{C}$ (dotted line) in an $\mathrm{EMIBF}_{4}$ ionic liquid electrolyte.

capacitances can be retained and the CV curves exhibit a nearly rectangular shape as it is typical for pure EDLCs with low electrolyte diffusion limitations. At scan rates of $50 \mathrm{mV} \mathrm{s}^{-1}$ and higher, redox reactions are too slow to contribute to the capacitance leading to the disappearance of the redox peaks.

We have additionally investigated the effect of an extension of the $\mathrm{CV}$ voltage range to $-2.5 \mathrm{~V}$ to $+2.5 \mathrm{~V}$ for the Alu 130derived hierarchical KC (Fig. S11 $\dagger$ ). The specific capacitance reaches even higher values of $174 \mathrm{~F} \mathrm{~g}^{-1}$ because the observed surface reactions now fully contribute to the capacitance values. However, at higher scan rates the CV still becomes rectangular indicating a reasonable stability. In spite of redox contributions present, it is known that the $\mathrm{EMIBF}_{4}$ IL can operate in a wide voltage window leading to high energy density. ${ }^{35,56}$

C-D measurements $(-2.0 \mathrm{~V}$ to $+2.0 \mathrm{~V})$ at a current density of $0.1 \mathrm{~A} \mathrm{~g}^{-1}$ and $20^{\circ} \mathrm{C}$ confirm the values observed in $\mathrm{CV}$ investigations showing high specific capacitances of $135 \mathrm{~F} \mathrm{~g}^{-1}$ and $124 \mathrm{~F} \mathrm{~g}^{-1}$ for KCs from Alu 130 and Aerosil 90 templates, respectively (Fig. $8 \mathrm{C}$ and $\mathrm{S} 12 \dagger$ ). As for the $1 \mathrm{M} \mathrm{H}_{2} \mathrm{SO}_{4}$ electrolyte, remarkable capacitance retentions of $75 \%$ are determined at ultrahigh current densities of $20 \mathrm{~A} \mathrm{~g}^{-1}$. The relative capacitance retentions of KCs significantly surpass those observed for highperformance polypyrrole-derived activated carbons, ${ }^{35}$ and other tuned mesoporous materials. Moreover, we have also performed C-D measurements with the Alu $130 \mathrm{KC}$-based EDLC at a high temperature of $70{ }^{\circ} \mathrm{C}$ (Fig. $8 \mathrm{C}$ and $\mathrm{S} 13 \dagger$ ). $\mathrm{A} \sim 10 \%$ increase of the specific capacitance is observed over the entire current density range due to the reduction of the viscosity of the electrolyte and an increase of its ionic conductivity. Compared to 


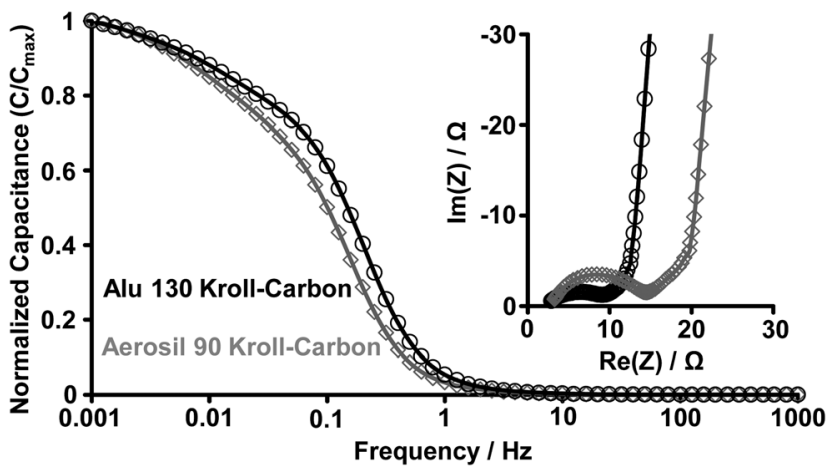

Fig. 9 Frequency response and Nyquist plots (inset) of the KCs from Alu 130 (black circles) and Aerosil 90 (grey diamonds) templates in the $\mathrm{EMIBF}_{4}$ ionic liquid electrolyte.

previously reported high-performance activated carbons showing a $\sim 20 \%$ increase of the capacitance even at $60{ }^{\circ} \mathrm{C},{ }^{35}$ the enhancement of the $\mathrm{KC}$ performance is relatively moderate indicating their outstanding electron transport performance even at room temperature.

In contrast to the aqueous electrolyte system, EIS measurements of the IL-based EDLCs show the presence of the typical $45^{\circ}$ segment due to the resistance of ions during diffusion into the bulk of electrode particles (Fig. 9, inset). The ESRs of the KCs are relatively equal due to comparable particle sizes (Fig. S6 ${ }^{\dagger}$ ) and their high purity and similar surface chemistry. Regarding the values of $f_{\max }$, both of the KCs show promising behaviour in the IL electrolyte system (Fig. 9). They can operate at frequencies as high as $0.15 \mathrm{~Hz}$ (KC from Alu 130) and $0.1 \mathrm{~Hz}$ (KC from Aerosil 90) being comparable with the high values of ordered mesoporous $\mathrm{CDCs}^{\mathbf{1 8}}$ and significantly exceeding those of many activated carbons ${ }^{\mathbf{1 6}, 57}$ even in cases where small mesopores are present. ${ }^{35}$

\section{Conclusions}

When tested for a new templating concept, silica and alumina nanoparticles confined within dense sucrose-derived carbon shells were found to be sufficiently reactive to be completely leached out during carbochlorination. As a result, the use of such particles as templates allow for the synthesis of micro- and mesoporous carbon materials with tunable mesopore volume. In our experiments, the resulting Kroll-carbons offer specific surface areas close to $2000 \mathrm{~m}^{2} \mathrm{~g}^{-1}$ and total pore volumes exceeding $3 \mathrm{~cm}^{3} \mathrm{~g}^{-1}$. The synthesis process is highly versatile for tailoring the pore morphology and diameter in a wide range by using various template particles. As the first example of a potential application, KCs were tested as electrode materials in two electrode EDLCs and show high specific capacitance values of $135 \mathrm{~F} \mathrm{~g}^{-1}$ in an aqueous electrolyte (1 M sulfuric acid) and $174 \mathrm{~F} \mathrm{~g}^{-1}$ in ionic liquid (1-ethyl-3-methylimidazolium tetrafluoroborate). High capacitance retentions (90\%) at high current densities can be achieved as a result of the hierarchical pore structure. Due to their efficient synthesis route as well as their promising electrochemical properties, KCs offer great potential for large-scale material production for high-power EDLCs (Fig. S14 $\dagger$ ). Moreover, they are hopeful candidates for other applications where mesoporous carbon materials are required (e.g. blood filtration, ${ }^{45,58}$ Li-S battery cathodes $^{\mathbf{1 1 , 4 2 , 5 0 , 5 9 , 6 0}}$ ) or for academic research.

\section{Acknowledgements}

We gratefully acknowledge the German academic exchange service (DAAD) for financial support. Georgia Tech team acknowledges the support of the Energy Efficiency \& Resources program of the Korea Institute of Energy Technology Evaluation and Planning (KETEP) funded by the Korea government Ministry of Knowledge Economy (grant 20118510010030).

\section{Notes and references}

1 L. Schlapbach and A. Zuttel, Nature, 2001, 414, 353.

2 Y. Gogotsi, R. K. Dash, G. Yushin, T. Yildirim, G. Laudisio and J. E. Fischer, J. Am. Chem. Soc., 2005, 127, 16006.

3 A. Taguchi and F. Schueth, Microporous Mesoporous Mater., 2004, 77, 1.

4 L. Borchardt, F. Hasche, M. R. Lohe, M. Oschatz, F. Schmidt, E. Kockrick, C. Ziegler, T. Lescouet, A. Bachmatiuk, B. Buechner, D. Farrusseng, P. Strasser and S. Kaskel, Carbon, 2012, 50, 1861.

5 L. R. Radovic and F. Rodriguez-Reinoso, Chem. Phys. Carbon, 1997, 25, 243.

6 S. Porada, L. Borchardt, M. Oschatz, M. Bryjak, J. S. Atchison, K. J. Keesman, S. Kaskel, P. M. Biesheuvel and V. Presser, Energy Environ. Sci., 2013, 6, 3700.

7 X. Wen, D. Zhang, L. Shi, T. Yan, H. Wang and J. Zhang, J. Mater. Chem., 2012, 22, 23835.

8 X. Wen, D. Zhang, T. Yan, J. Zhang and L. Shi, J. Mater. Chem. A, 2013, 1, 12334.

9 Y. Zhai, Y. Dou, D. Zhao, P. F. Fulvio, R. T. Mayes and S. Dai, Adv. Mater., 2011, 23, 4828.

10 H. Nishihara and T. Kyotani, Adv. Mater., 2012, 24, 4473.

11 N.-S. Choi, Z. Chen, S. A. Freunberger, X. Ji, Y.-K. Sun, K. Amine, G. Yushin, L. F. Nazar, J. Cho and P. G. Bruce, Angew. Chem., Int. Ed., 2012, 51, 9994.

12 E. Frackowiak, Q. Abbas and F. Béguin, J. Energy Chem., 2013, 2, 226.

13 M. Inagaki, H. Konno and O. Tanaike, J. Power Sources, 2010, 195, 7880.

14 M. Schroeder, M. Winter, S. Passerini and A. Balducci, J. Power Sources, 2013, 238, 388.

15 C. M. Ghimbeu, C. Decaux, P. Brender, M. Dahbi, D. Lemordant, E. Raymundo-Pinero, M. Anouti, F. Beguin and C. Vix-Guterl, J. Electrochem. Soc., 2013, 160, A1907.

16 L. Wei and G. Yushin, Nano Energy, 2012, 1, 552.

17 P. Simon and Y. Gogotsi, Nat. Mater., 2008, 7, 845.

18 M. Rose, Y. Korenblit, E. Kockrick, L. Borchardt, M. Oschatz, S. Kaskel and G. Yushin, Small, 2011, 7, 1108.

19 C. R. Perez, S.-H. Yeon, J. Segalini, V. Presser, P.-L. Taberna, P. Simon and Y. Gogotsi, Adv. Funct. Mater., 2013, 23, 1081. 
20 C. Portet, G. Yushin and Y. Gogotsi, J. Electrochem. Soc., 2008, 155, A531.

21 Y. Korenblit, M. Rose, E. Kockrick, L. Borchardt, A. Kvit, S. Kaskel and G. Yushin, ACS Nano, 2010, 4, 1337.

22 J. Chmiola, G. Yushin, Y. Gogotsi, C. Portet and P. Simon, Science, 2006, 313, 1760.

23 L. Wei, N. Nitta and G. Yushin, ACS Nano, 2013, 7, 6498.

24 E. Raymundo-Pinero, K. Kierzek, J. Machnikowski and F. Beguin, Carbon, 2006, 44, 2498.

25 J. S. Huang, B. G. Sumpter and V. Meunier, Chem.-Eur. J., 2008, 14, 6614.

26 W. T. Gu, N. Peters and G. Yushin, Carbon, 2013, 53, 292.

27 C. Portet, G. Yushin and Y. Gogotsi, Carbon, 2007, 45, 2511.

28 D. Pech, M. Brunet, H. Durou, P. H. Huang, V. Mochalin, Y. Gogotsi, P. L. Taberna and P. Simon, Nat. Nanotechnol., 2010, 5, 651.

29 J. S. Huang, B. G. Sumpter, V. Meunier, G. Yushin, C. Portet and Y. Gogotsi, J. Mater. Res., 2010, 25, 1525.

30 T. Kyotani, Carbon, 2000, 38, 269.

31 K. Kaneko, J. Membr. Sci., 1994, 96, 59.

32 L. Wei, M. Sevilla, A. B. Fuertes, R. Mokaya and G. Yushin, Adv. Energy Mater., 2011, 1, 356.

33 D. Hulicova-Jurcakova, M. Seredych, G. Q. Lu and T. J. Bandosz, Adv. Funct. Mater., 2009, 19, 438.

34 E. Raymundo-Pinero, M. Cadek and F. Beguin, Adv. Funct. Mater., 2009, 19, 1032.

35 L. Wei, M. Sevilla, A. B. Fuertes, R. Mokaya and G. Yushin, Adv. Funct. Mater., 2012, 22, 827.

36 W. T. Gu, M. Sevilla, A. Magasinski, A. B. Fuertes and G. Yushin, Energy Environ. Sci., 2013, 6, 2465.

37 T. Kyotani, Z. Ma and A. Tomita, Carbon, 2003, 41, 1451.

38 Y. Korenblit, A. Kajdos, W. C. West, M. C. Smart, E. J. Brandon, A. Kvit, J. Jagiello and G. Yushin, Adv. Funct. Mater., 2012, 22, 1655.

39 A. Kajdos, A. Kvit, F. Jones, J. Jagiello and G. Yushin, J. Am. Chem. Soc., 2010, 132, 3252.

40 H. Itai, H. Nishihara, T. Kogure and T. Kyotani, J. Am. Chem. Soc., 2011, 133, 1165.

41 V. Presser, M. Heon and Y. Gogotsi, Adv. Funct. Mater., 2011, 21, 810.

42 M. Oschatz, L. Borchardt, K. Pinkert, S. Thieme, M. R. Lohe, C. Hoffmann, M. Benusch, F. Wisser, C. Ziegler, L. Giebeler, M. Ruemmeli, J. Eckert, A. Eychmueller and S. Kaskel, Adv. Energy Mater., 2013, DOI: 10.1002/aenm.201300645, ahead of print.
43 M. Oschatz, L. Borchardt, M. Thommes, K. A. Cychosz, I. Senkovska, N. Klein, R. Frind, M. Leistner, V. Presser, Y. Gogotsi and S. Kaskel, Angew. Chem., Int. Ed., 2012, 51, 7577.

44 E. N. Hoffman, G. Yushin, T. El-Raghy, Y. Gogotsi and M. W. Barsoum, Microporous Mesoporous Mater., 2008, 112, 526.

45 G. Yushin, E. Hoffman, M. W. Barsoum, Y. Gogotsi, C. A. Howell, S. R. Sandeman, G. J. Phillips, A. W. Lloyd and S. V. Mikhalovsky, Biomaterials, 2006, 27, 5755.

46 G. Yushin, E. Hoffman, A. Nikitin, H. Ye, M. W. Barsoum and Y. Gogotsi, Carbon, 2005, 44, 2075.

47 C. Largeot, C. Portet, J. Chmiola, P.-L. Taberna, Y. Gogotsi and P. Simon, J. Am. Chem. Soc., 2008, 130, 2730.

48 Y. Lv, F. Zhang, Y. Dou, Y. Zhai, J. Wang, H. Liu, Y. Xia, B. Tu and D. Zhao, J. Mater. Chem., 2012, 22, 93.

49 M. Oschatz, E. Kockrick, M. Rose, L. Borchardt, N. Klein, I. Senkovska, T. Freudenberg, Y. Korenblit, G. Yushin and S. Kaskel, Carbon, 2010, 48, 3987.

50 M. Oschatz, S. Thieme, L. Borchardt, M. R. Lohe, T. Biemelt, J. Brückner, H. Althues and S. Kaskel, Chem. Commun., 2013, 49, 5832.

51 X. Li, Y. Cao, W. Qi, L. V. Saraf, J. Xiao, Z. Nie, M. Jaroniec, J.-G. Zhang, B. Schwenzera and J. Liu, J. Mater. Chem., 2011, 21, 16603.

52 K. G. Gallagher, G. Yushin and T. F. Fuller, J. Electrochem. Soc., 2010, 157, B820.

53 J. L. Xia, F. Chen, J. H. Li and N. J. Tao, Nat. Nanotechnol., 2009, 4, 505.

54 S. Osswald, J. Chmiola and Y. Gogotsi, Carbon, 2012, 50, 4880.

55 S. Boukhalfa, L. He, Y. B. Melnichenko and G. Yushin, Angew. Chem., Int. Ed., 2013, 52, 4618.

56 H. Kurig, A. Janes and E. Lust, J. Electrochem. Soc., 2010, 157, A272.

57 L. Wei and G. Yushin, J. Power Sources, 2011, 196, 4072 .

58 V. Presser, S.-H. Yeon, C. Vakifahmetoglu, C. A. Howell, S. R. Sandeman, P. Colombo, S. Mikhalovsky and Y. Gogotsi, Adv. Healthcare Mater., 2012, 1, 796.

59 J. T. Lee, Y. Zhao, S. Thieme, H. Kim, M. Oschatz, L. Borchardt, W. Cho, S. Kaskel and G. Yushin, Adv. Mater., 2013, 25, 4573.

60 X. Ji, K. Lee and L. F. Nazar, Nat. Mater., 2009, 8, 500. 